\title{
Combustion Characteristics of Nano Hydrotalcite Flame Retarded Ethylene Vinyl Acetate Copolymer
}

\author{
CHUANMEI JIAO, ZHENGZHOU WANG, ZHENG YE, YUAN HU, and \\ WEICHENG FAN \\ State Key Lab of Fire Science \\ University of Science and Technology of China \\ Anhui 230026, P.R. China
}

\begin{abstract}
The flame retardant effects of nano hydrotalcite (NLDH) on ethylene vinyl acetate copolymer (EVA) have been studied by using the limited oxygen index (LOI), UL-94 test, cone calorimeter test (CCT), and thermogravimetric analysis (TG). The LOI values of both EVA14/NLDH and EVA28/NLDH increase gradually with increasing of NLDH content. The LOI value of EVA14/NLDH is higher than that of EVA28/NLDH at the same additive level. In the UL-94 test, the difference of the VA content has no obvious effect on the combustion rating. From the CCT data, it can be seen that NLDH is not only an effective HRR reducer, but also a smoke suppressant. The TG and DTG data show that NLDH increases the thermal stability of EVA copolymer. Moreover, mechanical properties of the filled EVA composites were measured.
\end{abstract}

KEYWORDS: EVA, flame retardation, nano hydrotalcite, combustion behavior

\section{INTRODUCTION}

Ethylene vinyl acetate copolymer (EVA) is one of main polymers used in the wire and cable industry. EVA is easily flammable, so the flame retardation of it is widely studied $[1,2,3]$. Halogen-based compounds are one of the most effective flame retardant additives in polymers, but due to their negative characteristics, such as corrosiveness and toxicity, halogen-free flame retardation of polymers is increasingly concerned [4-7]. Metal hydroxides, mainly magnesium hydroxide ( $\mathrm{MH}$ ) and aluminum hydroxide (ATH) are widely used as halogen-free flame retardant additives of polymers. However, they have some disadvantages, for example, high loadings and poor compatibility with the polymeric matrix, which deteriorate the mechanical properties [8]. To deal with the problems caused by the high loadings of metal hydroxides, two methods are commonly used, namely, surface treatments of fillers and decrease of particle size. The surface modification of fillers using coupling agents can improve some mechanical properties, but in most cases leads to a decrease in the strength of the composites [9,10]. In recent years, nano metal hydroxides have aroused great attention.

Hydrotalcites are layered double hydroxides (LDHs). Their general formulas are $\left[\mathrm{M}^{\mathrm{II}}{ }_{1-\mathrm{x}}\right.$ $\left.\mathrm{M}^{\mathrm{III}}{ }_{\mathrm{x}}(\mathrm{OH})_{2}\right]^{\mathrm{x}+}\left[(\mathrm{Y})_{\mathrm{x} / \mathrm{m}}^{\mathrm{m}-}\right] \cdot \mathrm{nH}_{2} \mathrm{O}$, where $\mathrm{M}^{\mathrm{II}}$ is a divalent metal cation, $\mathrm{M}^{\mathrm{III}}$ is a trivalent metal cation, and $\mathrm{Y}$ stands for $\mathrm{m}$ valence inorganic or organic acid anions. Due to their layered structure and high anion exchange capacity, LDHs are now used in various applications. For example, a hydrotalcite with $\mathrm{Mg}^{2+}$ and $\mathrm{Al}^{3+}$ cations $\left(\mathrm{Mg} / \mathrm{Al}-\mathrm{CO}_{3} \mathrm{LDH}\right)$ can be used as a flame retardant additive [11]. $\mathrm{Mg} / \mathrm{Al}-\mathrm{CO}_{3} \mathrm{LDH}$ can simply be considered as 'a mixture' of MH and ATH. Many studies have found that MH and ATH have a synergistic effect in their flame-retarded polymers, so $\mathrm{Mg} / \mathrm{Al}-\mathrm{CO}_{3} \mathrm{LDH}$ probably 
has high flame retardant efficiency. In this paper, attempts were made to investigate the flame retardant effect of nano hydrotalcite (NLDH) in EVA.

\section{EXPERIMENTAL}

\section{Materials}

EVA14 (containing $14 \mathrm{wt} \%$ vinyl acetate) with a melt flow index (MFI) of $2.0 \mathrm{~g} / 10 \mathrm{~min}^{-1}$ was supplied by Beijing organic chemical plant. EVA28 (containing $28 \mathrm{wt} \%$ vinyl acetate) was bought from Sumitomo Chemical Co., Ltd. Hydrotalcite, with a median particle size of approximately $50 \mathrm{~nm}(90 \%$ of particles less than $100 \mathrm{~nm})$ treated with stearate interfacial modifier, was kindly provided by Beijing University of Chemical Technology, its typical formula is $\mathrm{Mg}_{6} \mathrm{Al}_{2}(\mathrm{OH})_{16} \mathrm{CO}_{3} 4 \mathrm{H}_{2} \mathrm{O}$, and the layer space of $\mathrm{NLDH}$ is $0.79 \mathrm{~nm}\left(\mathrm{~d}_{003}\right)$.

\section{Sample Preparation}

All compositions were melt compounded using a two-roll mill at about $120^{\circ} \mathrm{C}$ for $30 \mathrm{~min}$. After mixing, the mixtures were then compression molded at about $120^{\circ} \mathrm{C}$ into sheets (3 mm thickness) under a pressure of $10 \mathrm{MPa}$ for $10 \mathrm{~min}$. The sheets were cut into suitable size specimens for fire testing. The formulations used in the present work are listed in Table1.

Table 1. Formulations containing different additive levels.

\begin{tabular}{|c|c|c|c|}
\hline Sample & EVA14 (wt\%) & EVA28 (wt\%) & NLDH (wt\%) \\
\hline E14-DH0 & 100 & -- & -- \\
\hline E28-DH0 & -- & 100 & -- \\
\hline E14-DH33.3 & 66.7 & -- & 33.3 \\
\hline E14-DH44.5 & 55.5 & -- & 44.5 \\
\hline E14-DH50 & 50.0 & -- & 50.0 \\
\hline E14-DH54.5 & 45.5 & -- & 54.5 \\
\hline E14-DH60 & 40.0 & -- & 60.0 \\
\hline E28-DH33.3 & -- & 66.7 & 33.3 \\
\hline E28-DH44.5 & -- & 55.5 & 44.5 \\
\hline E28-DH50 & -- & 50.0 & 50.0 \\
\hline E28-DH54.5 & -- & 45.5 & 54.5 \\
\hline E28-DH60 & -- & 40.0 & 60.0 \\
\hline
\end{tabular}

\section{Analysis of Samples}

\section{Limiting Oxygen Index (LOI)}

The LOI measurements were carried out using a HC-2 type instrument (made in China) according to ASTMD 2863. The specimens used were $100 \times 6.5 \times 3 \mathrm{~mm}^{3}$.

\section{UL-94 Test}

The vertical test was performed on sheets $127 \times 12.7 \times 3 \mathrm{~mm}^{3}$ according to the UL-94 test standard. 
A cone calorimeter (Stanton Redcroft, England) was used to measure the flammability characteristics under a heat flux of $35 \mathrm{~kW} / \mathrm{m}^{2}$ according to ISO 5660 . The parameters measured include the rate of heat release (HRR), the time to ignition (IT), the specific extinction area (SEA), etc.

\section{Thermogravimetric Analysis (TG)}

The thermogravimetric (TG) experiments were carried out using a thermal analyzer (SHIMADZU, TA-50) in air at a heating rate of $10^{\circ} \mathrm{C} / \mathrm{min}$. The air (from the cylinder) flow was $20 \mathrm{ml} / \mathrm{min}$, and the aluminum pan was used in the TG experiment.

\section{Mechanical Properties}

The tensile strength and elongation at break were measured with a WD-20D Electronic Universal Testing Machine at the crosshead speed of $20 \mathrm{~mm} / \mathrm{min}$.

\section{Scanning Electron Microscopy (SEM)}

The SEM micrographs of the LDH filled EVA14 and EVA28 blends were analyzed by a AMRAY1000B scanning electron microscope. The specimens were cryogenically fractured in liquid nitrogen, and then sputter-coated with a conductive layer.

\section{RESULTS AND DISCUSSION}

\section{Combustion Behavior of EVA/NLDH Blends}

\section{Effect of NLDH Content on the LOI Values and UL-94 Rating of EVA/NLDH Blends}

Figure 1 presents the effects of different contents of NLDH on the LOI values of EVA14/NLDH and EVA28/NLDH blends. It can be seen that the LOI values of both EVA14/NLDH and EVA28/NLDH blends increase gradually with increasing of NLDH content. The LOI values of pure EVA14 and pure EVA28 are $17.5 \%$ and $18.5 \%$, respectively. However, it is interesting to find that the LOI value of EVA14/NLDH is higher than that of EVA28/NLDH at the same additive level. For example, the LOI value of EVA14/NLDH blend is 32\% at $44.5 \mathrm{wt} \% \mathrm{NLDH}$, whereas the corresponding value for EVA28/NLDH at $44.5 \mathrm{wt} \% \mathrm{NLDH}$ is $30.8 \%$. When the loading is $60 \mathrm{wt} \%$, the values of EVA14/NLDH and EVA28/NLDH blends are $43 \%$ and $42.2 \%$, respectively. For the same additive level, the LOI value of the EVA14/NLDH blends is $1 \sim 2 \%$ higher than that of the EVA28/NLDH blends. The above phenomenon may be explained by the release of acetic acid from the EVA decomposition, which was observed in the TG experiment, and whose amount was proportional to the vinyl acetate content of the copolymer [12]. Since hydrotalcite is basic, it can react with the acetic acid decomposed from EVA, leading to a decrease of the flame retardant effect of NLDH. The higher VA content of EVA, the more acetic acid released from the EVA decomposition, and thus the more serious influence on the flame retardation of NLDH. 


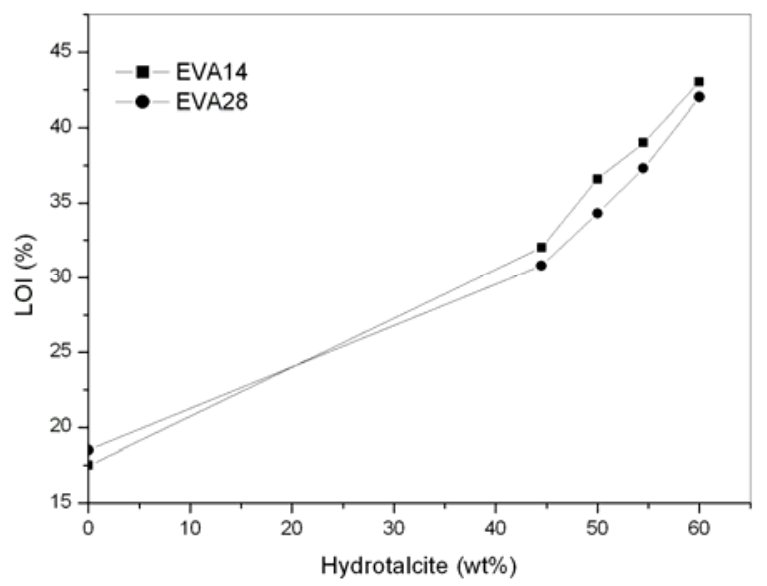

Fig. 1. Effect of NLDH concentration on the LOI values of the EVA14 and EVA28.

Table 2 lists the UL-94 test results of the EVA14/NLDH and EVA28/NLDH blends. It can be seen from Table 2 that for EVA14/NLDH blend with $54.5 \mathrm{wt} \%$ NLDH reaches the UL-94 V-1 rating, and the blend with $60 \mathrm{wt} \%$ NLDH reaches the UL-94 V-0 rating. Moreover, no dripping was observed for the blends at the additive NLDH over $50 \mathrm{wt} \%$. For the EVA28/NLDH blends the rating is similar to that of EVA14/NLDH at the same additive level. These results show that the difference of the VA content has no obvious effect on the UL-94 test results.

Table 2. The UL-94 test results of EVA/NLDH blends.

\begin{tabular}{|l|c|c|}
\hline \multicolumn{1}{|c|}{ Sample Code } & UL-94 rating & Phenomena \\
\hline E14-DH0 & Fail & Dripping \\
\hline E28-DH0 & Fail & Dripping \\
\hline E14-DH33.3 & Fail & Dripping \\
\hline E14-DH44.5 & Fail & Dripping \\
\hline E14-DH50 & Fail & No dripping \\
\hline E14-DH54.5 & V-1 & No dripping \\
\hline E14-DH60 & V-0 & No dripping \\
\hline E28-DH33.3 & Fail & Dripping \\
\hline E28-DH44.5 & Fail & Dripping \\
\hline E28-DH50 & Fail & No dripping \\
\hline E28-DH54.5 & V-1 & No dripping \\
\hline E28-DH60 & V-0 & No dripping \\
\hline
\end{tabular}

Dynamic Flammability Characterization of EVA14/NLDH Blends

The flammability of the EVA14/NLDH blends was also characterized by the cone calorimeter. The dynamic HRR curves for the EVA/NLDH blends with different NLDH contents are shown in Fig. 2. For the pure EVA (sample E14-DH0), there is a very sharp HRR peak, with a peak HRR (PHRR) value of $1813 \mathrm{~kW} / \mathrm{m}^{2}$, as listed in Table 3 . Moreover, the burning time of the pure EVA is very short within $250 \mathrm{~s}$ and its ignition 
time is $92 \mathrm{~s}$. However, the HRR peaks of all the flame retardant samples are relatively smooth with PHRR value below $469 \mathrm{~kW} / \mathrm{m}^{2}$, and the PHRR values decrease with the increase of the NLDH content. For example, the PHRR of sample E14-DH60 with $60 \mathrm{wt} \% \mathrm{NLDH}$ is $148 \mathrm{~kW} / \mathrm{m}^{2}$, which is only about one-twelfth of that of the pure EVA. From the data listed in Table 3, it can be seen that the ignition times of the EVA/NLDH blends increase greatly with increasing the NLDH content.

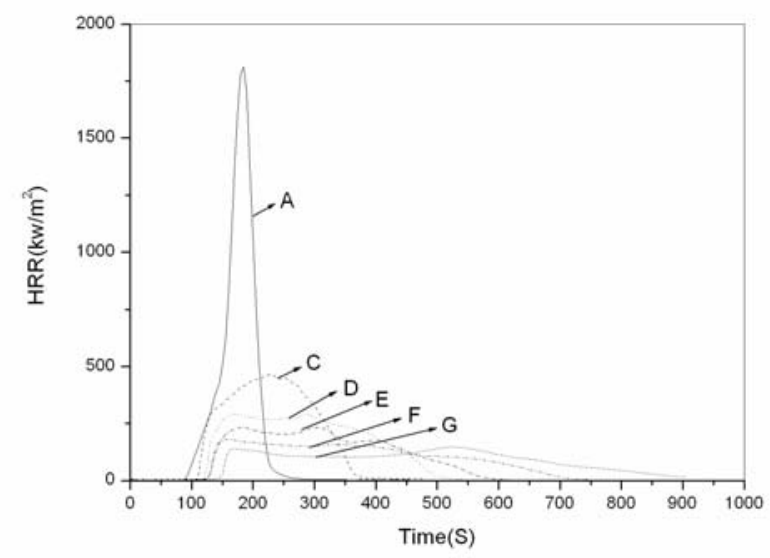

Fig. 2. Dynamic HRR curves of the EVA14 blends with different concentration of NLDH.

Table 3. Combustions behavior of EVA14/NLDH blends.

\begin{tabular}{|l|c|c|c|c|}
\hline Sample Code & IT (S) & $\begin{array}{c}\text { PHRR } \\
\mathbf{( k W / \mathbf { m } ^ { 2 } )}\end{array}$ & $\begin{array}{c}\text { PSEA } \\
\mathbf{( \mathbf { m } ^ { 2 } / \mathbf { k g } )}\end{array}$ & $\begin{array}{c}\text { Residues } \\
\mathbf{( \% )}\end{array}$ \\
\hline E14-DH0 & 92 & 1813 & 2396 & 0.38 \\
\hline E14-DH33.3 & 114 & 469 & 1024 & 19.8 \\
\hline E14-DH44.5 & 124 & 291 & 971 & 24.7 \\
\hline E14-DH50 & 127 & 232 & 896 & 27.4 \\
\hline E14-DH54.5 & 132 & 181 & 741 & 32.4 \\
\hline E14-DH60 & 151 & 148 & 721 & 36.2 \\
\hline
\end{tabular}

To understand the effect of the nanoparticle NLDH on the combustion of the flame retarded EVA blends, digital photos of the EVA/NLDH blend (sample E14-DH60) after the cone calorimeter test was taken (Fig. 3). It is clearly seen that much loose char was left after the combustion of the EVA/NLDH blend, which can prevent the heat transfer efficiently between the flame zone and the burning substrate, and thus retard the pyrolysis of the polymer. Moreover, nonflammable $\mathrm{CO}_{2}$ and water vapor produced in the decomposition of NLDH help to dilute combustible gases and to reduce the rate of burning in the gas phase. From above point of view, we can partly explain the reason that the PHRR of EVA/NLDH blends was lower than that of pure EVA. 


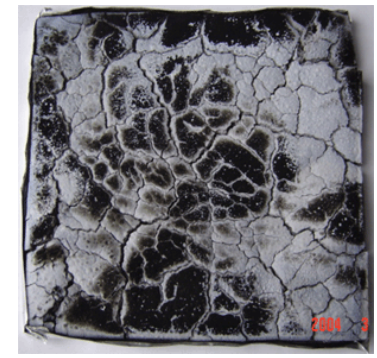

Fig. 3. Photos of sample E14-DH60 after cone calorimeter test.

NLDH is not only an effective HRR reducer, but also a smoke suppressant. As shown in Table 3, the peak specific extinction area (PSEA) values of the EVA/NLDH blends decrease with increasing the amount of NLDH. The smoke suppression of NLDH may be attributed to the water vapor and very fine oxide complexes produced from the decomposition of NLDH [13]. Reichle [14] et al. found that the calcinations of the hydrotalcite at high temperatures lead to a significant increase in both the surface area and the pore volume due to the loss of steam and carbon dioxide from the crystal surface. The smoke suppression of water is easily understood, and the formation of the fine oxide complexes covers the burning surface restricting the transfer of heat and smoke particles. As for the residue left after the burning of the EVA/NLDH blends, it was found that the content of the residue increases with increasing the amount of NLDH.

Comparing the flame retardation of NLDH with other nano additives, for example, nano magnesium hydroxide (NMH), we have found that $\mathrm{NLDH}$ is better than NMH in improving the LOI and UL 94 ratings of EVA, and that the PHRR of the EVA/NLDH blends are lower than that of the EVA/NMH blends [15]. In comparison with the flame retardation of nano silicates in polymers, recent reports indicate that these nano particles can result in a decrease in the PHRR and the rate of mass loss during combustion in a cone calorimeter, but they do not improve the LOI values and the UL-94 ratings of the polymer studied [16,17].

\section{Thermogravimetric Behavior of EVA14/NLDH Blends}

The TG and DTG curves of NLDH are presented in Fig. 4. It can be seen that NLDH exhibits four stages of weight loss. The first step below $250^{\circ} \mathrm{C}$ is attributed to loosely bound water in the interlayer space with a maximum rate of weight loss at $209^{\circ} \mathrm{C}$. The second and third steps locate in the range of $250^{\circ} \mathrm{C}-550^{\circ} \mathrm{C}$ with maximum rates of weight loss at $311^{\circ} \mathrm{C}$ and $360^{\circ} \mathrm{C}$, respectively, which belong to the simultaneous dehydroxylation and decarbonation of the lattice. The weight loss at those two stages is $\sim 23 \%$. Beyond $580{ }^{\circ} \mathrm{C}$ (the fourth step), metal oxide formed from decomposition begins to sinter. From the process of above decomposition, it can be seen that NLDH decomposes in different temperature sectors, so NLDH exerts its flame retardant role in a wide temperature range.

Figure 5 shows the TG and DTG curves of the virgin EVA14 and EVA14/NLDH blend (sample E14-DH50). It is noted that the decomposition process of the virgin EVA is composed of two main weight loss steps. The first step involves the decomposition of the acetate groups in EVA side chains, which takes place in the range of $260{ }^{\circ} \mathrm{C} \sim 395{ }^{\circ} \mathrm{C}$ with a maximum rate of weight loss at $370.4^{\circ} \mathrm{C}$. The second step corresponding to the scission of the main chains of EVA is located in the range of $395^{\circ} \mathrm{C} \sim 608^{\circ} \mathrm{C}$ with a maximum rate of weight loss at $442.7^{\circ} \mathrm{C}$. In the case of the EVA/NLDH blend, its 
decomposition is relatively complicated, especially in the initial degradation stage. The temperatures of the maximum rates of weight loss in four decomposition steps are $272.7^{\circ} \mathrm{C}, 344.0^{\circ} \mathrm{C}, 381.6^{\circ} \mathrm{C}$ and $486.4^{\circ} \mathrm{C}$, respectively. As for the residues left after the decomposition, the virgin EVA is almost decomposed completely, and the residue for the EVA/NLDH blend (sample E14-DH50) is about 28\%.

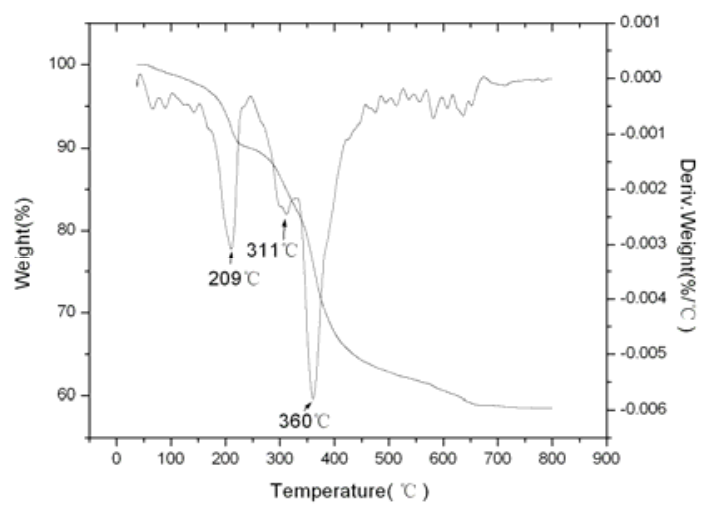

Fig. 4. TG and DTG curves of virgin NLDH.
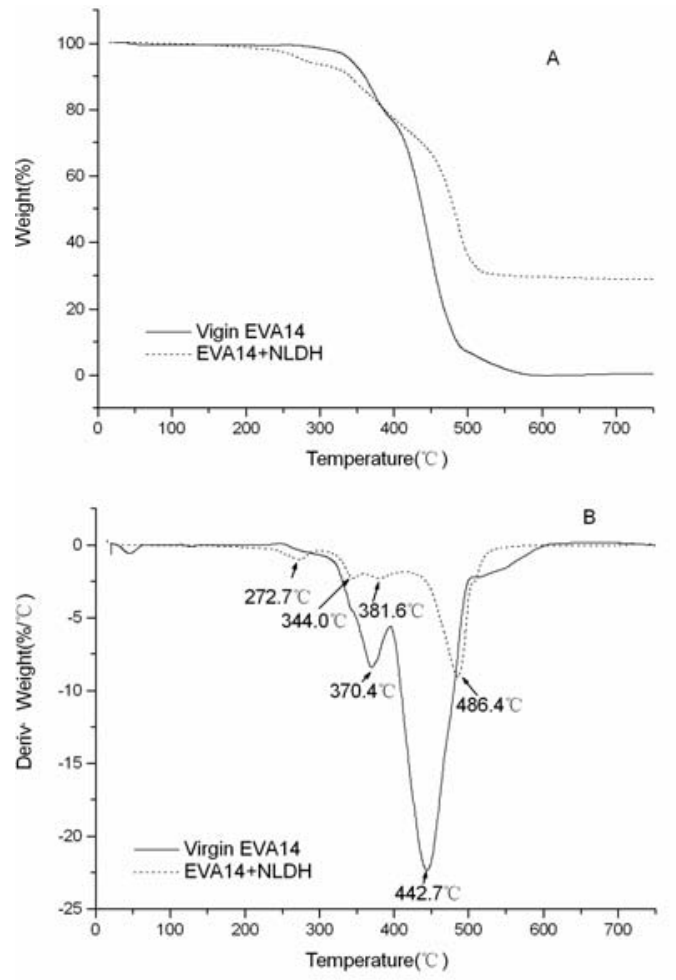

Fig. 5. TG (A) and DTG (B) curves of virgin EVA14 and EVA14+NLDH blend (sample E14-DH50). 


\section{Mechanical Properties of EVA/NLDH Blends}

The tensile strength $\left(\sigma_{b}\right)$ and elongation at break $\left(\varepsilon_{b}\right)$ of the pure EVA and EVA/NLDH blends are summarized in Table 4. It is observed that the $\varepsilon_{\mathrm{b}}$ values of both EVA14/NLDH blends and EVA28/NLDH blends decrease with increasing the content of NLDH. The reduction in the $\varepsilon_{\mathrm{b}}$ may be due to the poor compatibility between the filler and the polymer substrate in blends. However, the $\varepsilon_{\mathrm{b}}$ values of EVA28/NLDH are much higher than that of EVA14/NLDH, which may be caused by the difference of the VA content between EVA14 and EVA28. The polarity of EVA28 is stronger than that of EVA14, leading to the better compatibility between NLDH and EVA28.

It is interesting to find that the $\sigma_{\mathrm{b}}$ values in EVA14/NLDH system and EVA28/NLDH system first decrease at low additive levels (less than about $50 \mathrm{wt} \%$ ) compared with that of the control samples EVA14 and EVA28 resin, respectively. Then the values increase slightly when the content of the NLDH is more than $50 \mathrm{wt} \%$. The slight increase in the $\sigma_{b}$ value at higher loadings of the nano filler is probably attributed to the reinforcing effect of the nano particle.

Figure 6 shows SEM micrographs of the fracture surfaces of the EVA14/NLDH blend (sample E14-DH60) and EVA28/NLDH blend (sample E28-DH60). It can be noted from Fig. 6 (A) that the fracture surface of sample E14-DH60 is coarse, and many debonded NLDH particles are seen on the fracture surface indicating that the adhesion between flame retardant additive and EVA14 is poor. However, Fig. 6 (B) shows that NLDH particles are well dispersed into the matrix of EVA28 because no clear interface between NLDH and EVA28 can be observed. Moreover, the TEM picture (not shown here) of sample E14-DH50 (containing $50 \mathrm{wt} \% \mathrm{NLDH}$ ) indicates that the dispersion of NLDH particles in the EVA resin is generally good. The improvement of the adhesion between NLDH and EVA28 results in an increase in the mechanical properties of EVA28/NLDH compared with EVA14/NLDH, as shown in Table 4.

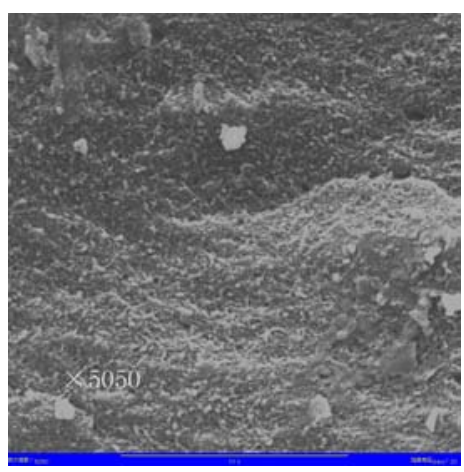

(A)

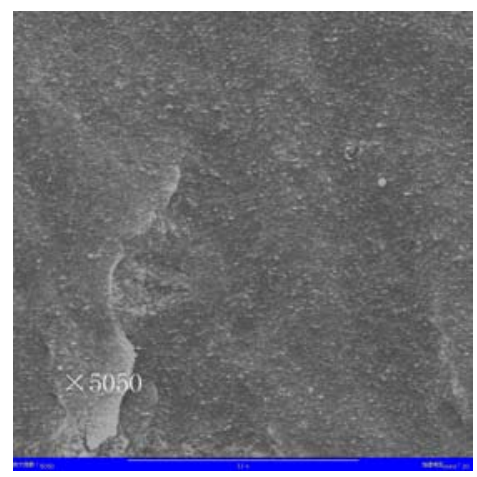

(B)

Fig. 6. SEM micrographs of E14-DH60 (A) and E28-DH60 (B). 
Table 4. Mechanical properties $\sigma_{\mathrm{b}}$ and $\varepsilon_{\mathrm{b}}$ of EVA blends.

\begin{tabular}{|l|c|c|}
\hline \multicolumn{1}{|c|}{ Sample } & $\boldsymbol{\sigma}_{\mathbf{b}} \mathbf{( M P a )}$ & $\boldsymbol{\varepsilon}_{\mathbf{b}} \mathbf{( \% )}$ \\
\hline E14-DH0 & 21.2 & 1325.8 \\
\hline E28-DH0 & 26.5 & 1688.5 \\
\hline E14-DH33.3 & 14.2 & 525.9 \\
\hline E14-DH44.5 & 10.8 & 300.9 \\
\hline E14-DH50 & 10.4 & 224.6 \\
\hline E14-DH54.5 & 11.2 & 136.8 \\
\hline E14-DH60 & 11.4 & 42.5 \\
\hline E28-DH33.3 & 14.8 & 953.8 \\
\hline E28-DH44.5 & 11.9 & 723.3 \\
\hline E28-DH50 & 11.5 & 477.5 \\
\hline E28-DH54.5 & 11.8 & 372.3 \\
\hline E28-DH60 & 12.4 & 237.3 \\
\hline
\end{tabular}

\section{CONCLUSIONS}

The flame retardation of EVA14 and EVA28 using the NLDH additive has been evaluated comprehensively. From the LOI test, it can be seen that the LOI value of EVA14/NLDH is higher than that of EVA28/NLDH at the same additive level. According to the results of the UL-94 test, the difference of the VA content has no obvious effect on the UL-94 rating. Using NLDH as a flame retardant additive in EVA, very high loadings (about $60 \mathrm{wt} \%$ ) are still needed to meet an adequate level of flame retardant property. The addition of NLDH to EVA is detrimental to the mechanical properties of the filled EVA14 and EVA28 blends at high loadings, but the EVA28/NLDH blends have better mechanical properties than the ones of the EVA14/NLDH blends.

The CCT data show that NLDH is not only an effective HRR reducer, but also a smoke suppressant. The thermogravimetric analysis shows that NLDH has several decomposition steps, indicating that $\mathrm{NLDH}$ as a flame retardant can exerts its flame retardant action in the whole decomposition temperature ranges of EVA.

\section{ACKNOWLEDGEMENT}

The financial support from the China National Key Basic Research Special Funds project (No. 2001CB409600) and from the National Natural Science Foundation of China (No. 50273036) is greatly acknowledged.

\section{REFERENCES}

[1] Beyer, G., "Flame Retardant Properties of EVA-nanocomposites and Improvements by Combination of Nanofillers with Aluminium Trihydrate,” Fire and Materials, 25: 193-197, 2001.

[2] Riva, A., Canimo, G., Fomperie, L., and Amiqouet, P., "Fire Retardant Mechanism in Intumescent Ethylene Vinyl acetate Compositions,” Polymer Degradation and Stability, 82: 341-346, 2003. 
[3] Zilberman, J., Hull, T.R., Price, D., Milnes, G.J., and Keen, F., "Flame Retardancy of Some Ethylene-vinyl Acetate Copolymer-based Formulations,” Fire and Materials, 24: 159-164, 2000.

[4] Sen, A.K., Mukheriee, B., Bhattacharya, A.S., Sanghi, L.K., De, P.P., and Bhowmick, K., "Preparation and Characterization of Low-halogen and Nonhalogen Fire-resistant Low-smoke (FRLS) Cable Sheathing Compound from Blends of Functionalized Polyolefins and PVC," Journal of Applied Polymer Science, 43: 1673-1684, 1991.

[5] Carpentier, F., Bourbigot, S., Le Bras, M., Delobel, R., and Foulon, M., "Charring of Fire Retarded Ethylene Vinyl Acetate Copolymer-magnesium Hydroxide/Zinc Borate Formulations,” Polymer Degradation and Stability, 69: 83-92, 2000.

[6] Wang, Z.Z., Qu, B.J., Fan, W.C., and Huang, P., "Combustion Characteristics of Halogen-free Flame-retarded Polyethylene Containing Magnesium Hydroxide and Some Synergists,” Journal of Applied Polymer Science, 81: 206-214, 2001.

[7] Li, Z.Z., Qu, B.J., "Flammability Characterization and Synergistic Effects of Expandable Graphite with Magnesium Hydroxide in Halogen-free FlameRetardant EVA Blends,” Polymer Degradation and Stability, 81: 401-408, 2003.

[8] Rothon, R.N., Hornsby, P.R., "Flame Retardant Effects of Magnesium Hydroxide,” Polymer Degradation and Stability, 54: 383-385, 1996.

[9] Cook, M., Harper, J.F., “Influence of Magnesium Hydroxide Morphology and Surface Coating on Physical and Mechanical Properties of Heterophasic Polypropylene,” Plastic, Rubber and Composites Processing and Application, 25: 99-105, 1996.

[10] Demjen, Z., Pukanszky, B., "Effect of Surface Coverage of Silane Treated CaCO3 on the Tensile Properties of Polypropylene Composites," Polymer Composites, 18: 741-747, 1997.

[11] Wang, X.D., Zhang, Q., "Effect of Hydrotalcite on the Thermal Stability, Mechanical Properties, Rheology and Flame Retardance of Poly (Vinyl Chloride)," Polymer International, 53: 698-707, 2004.

[12] Serrano, D.P., Aguado, J., Escola, J.M., Rodriguez, J.M., Morselli, L., and Orsi, R., "Thermal and Catalytic Cracking of a LDPE-EVA Copolymer Mixture,” Journal of Analytical and Applied Pyrolysis, 68-69: 481-494, (2003).

[13] Malherbe, F., Forano, C., Besse, J.P., "Use of Organic Media to Modify the Surface and Porosity Properties of Hydrotalcite-like Compounds,” Microporous Materials, 10: 67-84, 1997.

[14] Reichle, W.T., Kang, S.Y., and Everhardt, D.S., "The Nature of the Thermal Decomposition of a Catalytically Active Anionic Clay Mineral,” Journal of Catalysis, 101: 352-359, 1986.

[15] Jiao, C.M., Wang, Z.Z., Ye, Z., Hu, Y., and Fan., W.C., "Flame Retardation of EthyleneVinyl Acetate Copolymer Using Nano Magnesium Hydroxide and Nano Hydrotalcite,” Journal of Fire Sciences (in press). 
[16] Wang, S.F., Hu, Y., Zong, R.W., Tang, Y., Chen, Z.Y., and Fan, W.C., "Preparation and Characterization of Flame Retardant ABS/Montmorillonite Nanocomposite,” Applied Clay Science, 25: 49-55, 2004.

[17] K, J., Lee, K., Lee K., Bae, J., Yang, J., and Hong, S., "Studies on the Thermal Stabilization Enhancement of ABS; Synergistic Effect of Triphenyl Phosphate Nanocomposite, Epoxy Resin, and Silane Coupling Agent Mixtures,” Polymer Degradation and Stability, 79: 201-207, 2003. 
